\title{
Studying local expressions of subjective well-being
}

\section{Weckroth, Mikko Teemu Kalervo}

2013-01-04

Weckroth , M T K 2013 , ' Studying local expressions of subjective well-being ' , Regional Insights, vol. 4 , no. 1 , pp. 4 .

http://hdl.handle.net/10138/42058

submittedVersion

Downloaded from Helda, University of Helsinki institutional repository.

This is an electronic reprint of the original article.

This reprint may differ from the original in pagination and typographic detail.

Please cite the original version. 


\section{Studying local expressions of}

\section{subjective well-being}

Mikko Weckroth argues that regional science should take greater account of the importance of concepts of well-being, and how to measure it more effectively.

- xamining the interplay between happiness and location is one of the most intriguing projects a person can undertake. While it is easy to agree on the validity of this statement on a personal level, I argue that it can also be formulated into questions that can - and should - be approached using scientific methods. Before starting to work on my PhD dissertation, I began developing a database of firsthand experiences regarding spatial variance and the distribution of well-being on a global scale. This process included, for example, interviewing Somalian family reunion applicants at the Embassy of Finland in Addis Ababa, working in poverty reduction projects in an NGO in Tanzania. While trying to tie these experiences and practices to theory, I have been an eager scholar of disciplines such as social science history, intercultural communications and trans-disciplinary urban studies. In retrospect, I find it somehow logical that my $\mathrm{PhD}$ thesis seeks to analyze the patterns and processes affecting spatial expressions of subjective well-being (SWB).

Our understanding of the defining and measuring of well-being has been dominated by objective data presented as consensus of populations. However, during the last two decades, as the analysis of SWB has developed into a substantial component in well-being studies, social indicators combining both objective and subjective measures have evolved. Analyses based on these indicators are usually presented as rankings and comparisons at the national level. Recent studies have shown that when moving to smaller scales, subjective and objective measures of well-being start to separate to an increasing extent. Based on this, as well as my own perceptions, my PhD research is aiming to contribute to this emerging gap in knowledge. Consequently, my motivation for researching this subject arises from discontent at the existing empirical-based theories offering demographic and socio-economic attributes as comprehensive explanatory variables behind the spatial variance in subjective well-being.

Analyses based on descriptive statistics, drawing from national happiness surveys, suffer from problems related to generalisation and the utilisation of their results. Examining national mean values of happiness can, nevertheless, offer a solid starting point for discussion on mechanisms transforming objective resources of well-being into subjective experiences. However, since the analysis of subjective well-being often questions economic growth as an overall indicator for societal progress, the definition and measurement of well-being easily turns into a political and ideological debate. Even if capable of avoiding this conflict, any politics or policies promoting happiness inside a nation state would inevitably be based on a utilitarian approach aimed at increasing the cumulative account of national happiness. Consequently, national analyses are also blind to the variation in well-being within nations. Thereby, analysis of SWB at the subnational level has a possibility to open up new ways of thinking about both measuring and responding to spatial inequalities.

My PhD aims to embed the method of empirical happiness study into the context of a city region. Certain values related to housing and the living environment seem to connect to the evaluated components of well-being and happiness. Additionally, the connection between subjective well-being and location appears stronger in certain areas. These results are drawn from an analysis of a comparative case study of an 'urban village' and a 'gated community' in the Greater Helsinki Region, Finland. SWB appear to have a higher explanatory value in a more heterogenic neighbourhood representing certain values and characteristics connected with urban living, even while controlling for socio-demographic factors. Thereby, these results may also offer some contribution to practices of urban planning and housing.

The main arguments could be formulated as:

I) The concept of well-being should be integrated as a terminal objective behind urban policies promoting competitiveness and economic growth. The effectiveness of these policies should be examined and updated against our current understanding of well-being.

2) Consequently, questions on defining and measuring wellbeing become essential. Simultaneous mapping of objective and subjective measures of well-being could illustrate what type of well-being and for whom different forms of regional development generate.

3) Regional study is in essence an interdisciplinary science. However, spatial cross-disciplinary analysis of SWB demands opening up even further, drawing from sociology, behavioral economics, philosophy, and positive psychology. This requires a constructive discourse between different scholars and paradigms in regional analysis.

My PhD aims to contribute to this emerging knowledge gap, motivated by discontent at existing empirical-based theories using demographic and socio-economic attributes to comprehensively explain spatial variance in subjective well-being. The context-orientated well-being studies could address this question of scaling by controlling the impact of social comparison and the cultural context on the validity of happiness studies. The analysis of spatial sample survey data can also indicate location-based factors connected with subjective well-being. Furthermore, they could reveal new dimensions of the concept of well-being itself that are non-detectable from analyses operating at larger scales. In my opinion, addressing this task is an important and significant aim for any discipline, single study or individual researcher. 